\title{
Stock Prices and Exchange Rates in Indonesia: Further Evidence
}

\author{
Bakri Abdul Karim, Josephine Yau Hwang, Norlina Kadri and Dzul Hadzwan Husaini \\ Faculty of Economics and Business, Universiti Malaysia Sarawak (UNIMAS)
}

\begin{abstract}
The paper examines the relationship between stock prices and exchange rates for the case of Indonesia. The study uses daily and weekly data for the period January 1998 to December 2007. We employed Toda and Yamamoto (1995) Granger non-causality test in both bivariate and multivariate setting to examine the relationship between stock prices and exchange rates. The results of this study suggest a strong evidence of bi-directional causality between these two financial variables. The results have implications for investors, practitioners and policy makers.
\end{abstract}

Keywords: Exchange rates, Stock Prices, Causality, Indonesia

\section{INTRODUCTION}

Theoretically, there are two contrasting views on the relationship between stock prices and exchange rate. The traditional approach believes that exchange rates Granger cause stock prices. The fluctuations in the exchange rate can substantially affect the value of firms, through the changes in the terms of competition, input prices and the value of foreign currency denominated assets (Bodnar and Gentry, 1993). Eventually the changes will affect the firm's future cash flows and stock prices in general. On the other hand, the portfolio approach believes that stock prices Granger cause exchange rates. Changes in stock prices may influence the movements in the exchange rate, via firms' portfolio adjustments (Bahmani-Oskooee and Sohrabian, 1992) or outflow of capital (Qiao, 1996). Thus, changes in stock prices lead to the changes in the exchange rate due to the changes in the demand and supply of foreign currency.

There are quite a number of studies written on the relations between stock prices and exchange rate. The findings, however, the existing literature is inconclusive regarding the causal relationship between stock prices and exchange rate (see Aggarwal, 1981; Abdalla and Murinde, 1997; and Nieh and Lee, 2001). Various methodologies have been employed which include simple regression analysis as well as the recent technique of time series analysis.

This study aims to empirically examine the causal relation between the stock prices and exchange rates in Indonesia. This study could contribute to the literature in the following ways. First, the study considers both bivariate and multivariate models. We note that the majority of earlier studies have focused on the bivariate framework. The omission of important variables may end up with spurious results. Second, this study utilizes both daily data and weekly data over the period in order to examine what happens as we move from higher-frequency to lower-frequency data. In particular, we consider whether the lower-frequency data contains less noise and relatively more information to estimate the relationship. Thus, we hope, this study could shed some light on the issue of dynamic relationship between stock prices and exchange rates.

The relationship between the two financial variables is very crucial for profitable and strategic investment decisions that enable the investors to adjust their allocation of portfolio as a result of exchange rate policy shift. For the policy makers, a significant link between exchange rate and stock market suggests that stock market behaviour may have significant consequence on exchange rate policies. 
The rest of the article is organized as follows. The next section provides literature review, whereas the third section describes empirical framework and description of the data. The fourth section offers empirical results. Finally, the last section presents conclusion.

\section{LITERATURE REVIEW}

Recently, studies have focused on the interactions or the directions of causality between exchange rates and stock prices for major industrial economies and emerging markets. The dynamic relationships between stock prices and exchange rates have been empirically analyzed for the past three decades and the result and findings are mixed as to the significance and the direction of influences between exchange rates and stock prices.

Morley and Pentecost (2000) investigated the nature of the relationship between stock prices and spot exchange rates for G-7 countries of Canada, France, Germany, Italy, Japan, UK and the US during the period from 1982 to 1994 . They found that traditional econometric techniques show little correlation between bilateral exchange rates and stock prices. They concluded it is due to the stock prices and exchange rates do exhibit common cycles but do not exhibit common trends. Subsequently, Nieh and Lee (2001) conducted a study on G-7 countries for the sample period from October 1, 1993 to February 15, 1996, of daily closing stock market indices and foreign exchange rates to explore the dynamic relationships between the stock prices and the exchange rates for each G-7 country. They found significant short-run dynamics and no long-run relationship between stock prices and exchange rates for the G-7 countries. In addition, Yang and Doong (2004) explored the nature of the mean and volatility transmission mechanism between stock and foreign exchange markets for the G-7 countries. Using weekly data and a bivariate EGARCH framework, they found evidence that changes in stock prices will affect future exchange rate changes, but movements in exchange rates have less direct impact on future movements of stock prices. The implication is particularly important to international portfolio managers when devising hedging and diversification strategies for their portfolios.

There are also economists and practitioners who are interested to explore the emerging markets. For instance, Abdalla and Murinde (1997) investigated the interactions between exchange rate and stock prices in the emerging market of India, Korea, Pakistan and the Philippines. Using of monthly data observations from 1985-1994, they found the exchange rates Granger-cause stock prices in Korea, Pakistan and India, whereas stock prices Granger-cause exchange rates in the Philippines. For Bangladesh, India, Pakistan and Sri Lanka, using daily data from 1995 to 2001 and Engle-Granger twostep and Johansen cointegration methods, Smyth and Nandha (2003) found evidence no long-run equilibrium relationship between these two financial variables in any of the four countries. Additionally, Granger causality tests found that there is unidirectional causality running from exchange rates to stock prices in India and Sri Lanka, but in Pakistan and Bangladesh exchange rates and stock prices are independent.

A number of empirical studies have examined the relationship between exchange rates and share prices for various markets and timeframes. For instant, Ajayi et al. (1998) found uni-directional causality from stock prices to exchange rates in developed markets (Canada, Germany, France, Italy, Japan and UK), but their results for emerging markets were mixed. They found bi-directional causality in Taiwan, causality running from stock prices to the exchange rate in Indonesia and the Philippines; from the exchange rate to stock prices in Korea and no significant causal relationship in Hong Kong, Singapore, Thailand and Malaysia. For Asia market, Granger et al. (2000) found that exchange rates lead stock prices in South Korea; stock prices lead exchange rates in Hong Kong, Malaysia, Philippines, Singapore, Thailand and Taiwan. However, there are no support for any relationship in Japan and Indonesia. 
There exist the bidirection volatility spillovers effects between the two markets, indicating the past innovations in stock market have the great effect on future volatility in foreign exchange market, and vice versa (Zhao, 2010). Saiti et al. (2014). Wavelet decomposition, exchange rate leads the stock price. The exchange rate returns and stock index returns have a bidirectional relationship in this period at longer horizons (Hamrita and Trifi, 2011).

Our empirical results show a significant causal relation from exchange rates to stock prices for Hong Kong, Japan, Malaysia, and Thailand before the 1997 Asian financial crisis. Further, while no country shows a significant causality from stock prices to exchange rates during the Asian crisis, a causal relation from exchange rates to stock prices is found for all countries except Malaysia (Pan, Fok and Liu, 2007). Our findings also indicate that the linkages vary across economies with respect to exchange rate regimes, the trade size, the degree of capital control, and the size of equity market. Overall the findings from various researchers are contradictory. There is still no consensus among researchers on the relationship between exchange rates and stock prices.

\section{METHODOLOGY AND DATA}

We use Toda and Yamamoto (1995) Granger non-causality test to examine the relationship between stock prices and exchange rates. Granger non-causality test in an unrestricted vector autoregressive (VAR) model can be conducted by testing whether some parameters are jointly zero. Toda and Yamamoto (1995) involve a modified Wald (MWALD) test in an augmented VAR model and avoid the problems due to the sensitivity of stationarity or cointegration tests by ignoring any possible non-stationary or cointegration between series when testing for causality. In addition, it utilizes a standard VAR in the levels of the variables. Thus, we could minimize the risks associated with possibly wrongly identifying the orders of integration of the series, or the presence of cointegration and minimizes the distortion of the tests' sizes as a result of pre-testing (Mavrotas and Kelly 2001).

This test utilizes the Modified WALD (MWALD) for testing linear restriction on the parameters and it has an asymptotic $\chi^{2}$ distribution when a VAR $\left(k+d_{\max }\right)$ is estimated. Here $d_{\max }$ is the maximum degree of integration to occur in the system and $\mathrm{k}$ is the optimal lag length. Toda and Yamamoto (1995) noted that, for $\mathrm{d}=1$, the lag selection procedure is always valid since $\mathrm{k} \geq 1=\mathrm{d}$. If $\mathrm{d}=2$, the procedure is valid unless $\mathrm{k}=1$. In addition, this procedure is valid regardless whether a series is $\mathrm{I}(0), \mathrm{I}(1)$ or $\mathrm{I}(2)$, noncointegrated or cointegrated of an arbitrary order. Moreover, Zapata and Rambaldi (1997) provide evidence that the MWALD test has a comparable performance in size and power to the LR and WALD tests if the correct number of lags for estimating $\mathrm{k}+\mathrm{d}_{\max }$ is identified and no important variables are omitted, provided a sample of 50 observations is available. To implement the causality test, the following augmented VAR $(p+d)$ model to be estimated:

$$
y_{t}=\alpha+A_{1} y_{t-1}+\ldots \ldots+A_{p} y_{t-p}+A_{p+d} y_{t-p-d}+\varepsilon_{t}
$$

Where $\mathrm{y}_{\mathrm{t}}, \alpha$ and $\varepsilon$ are $\mathrm{n}$-dimensional vectors. $\mathrm{A}$ is an $\mathrm{n} \mathrm{x}$ matrix of parameter lag $\mathrm{p}$ and $\mathrm{d}$ is the maximal order of integration of the variables. We use the Akaike Information Criterion (AIC) to determine the order p. Given the focus on the relationship between stock price and exchange rate, respectively, the equations corresponding to stock price and respective exchange rate are shown below (with the assumption optimum lag length is one):

Bivariate model:

$$
S P_{t}=\alpha_{0}+\sum_{i=1}^{k} \beta_{1 i} S P_{t-i}+\sum_{j=k+1}^{d \max } \beta_{2} S P_{t-j}+\sum_{i=1}^{k} \lambda_{1 i} E R_{t-i}+\sum_{j=k+1}^{d \max } \lambda_{2} E R_{t-j}+\varepsilon_{1 t}
$$




$$
E R_{t}=\bar{\alpha}_{0}+\sum_{i=1}^{k} \bar{\beta}_{1 i} S P_{t-i}+\sum_{j=k+1}^{d \max } \bar{\beta}_{2} S P_{t-j}+\sum_{i=1}^{k} \bar{\lambda}_{1 i} E R_{t-i}+\sum_{j=k+1}^{d \max } \bar{\lambda}_{2} E R_{t-j}+\varepsilon_{2 t}
$$

Multivariate model:

$$
\begin{aligned}
& S P_{t}=\alpha_{0}+\sum_{i=1}^{k} \phi_{1 i} S P_{t-i}+\sum_{j=k+1}^{d \max } \phi_{2} S P_{t-j}+\sum_{i=1}^{k} \delta_{1 i} E R_{t-i}+\sum_{j=k+1}^{d \max } \delta_{2} E R_{t-j}+\sum_{i=1}^{k} \varphi_{1 i} U S_{t-i}+\sum_{j=k+1}^{d \max } \varphi_{2} U S_{t-j}+\varepsilon_{1 t} \\
& E R_{t}=\alpha_{0}+\sum_{i=1}^{k} \bar{\phi}_{1 i} S P_{t-i}+\sum_{j=k+1}^{d \max } \bar{\phi}_{2} S P_{t-j}+\sum_{i=1}^{k} \bar{\delta}_{1 i} E R_{t-i}+\sum_{j=k+1}^{d \max } \bar{\delta}_{2} E R_{t-j}+\sum_{i=1}^{k} \bar{\varphi}_{1 i} U S_{t-i}+\sum_{j=k+1}^{d \max } \bar{\varphi}_{2} U S_{t-j}+\varepsilon_{2 t}
\end{aligned}
$$

Where SP is stock price; ER represents exchange rate; and US refers to S\&P500. If there is unidirectional Granger-causality from the exchange rate to stock price thus:

$$
\begin{aligned}
& \lambda_{1} \neq 0 \forall_{i} \text { in equation (2) } \\
& \delta_{1} \neq 0 \forall_{i} \text { in equation (4) }
\end{aligned}
$$

Daily and weekly data for exchange rates and stock prices spanning from January 1998 to December 2007 are employed. End of day spot exchange rate vis-à-vis US dollar (ER), the Jakarta Composite Index (SP) and the Standard \& Poor 500 (US) index are utilized in this study. The variables are obtained from Bloomberg database and transformed into natural logarithm.

\section{EMPIRICAL FINDINGS}

Prior to implement the non-causality test, we have to determine the degree of integration of the variables. Accordingly, the standard Augmented Dickey-Fuller (ADF) and Phillips-Perron (PP) unit root tests are conducted to determine the order of integration for stock prices and exchange rates. Table 1 reports the $\mathrm{ADF}$ and PP tests statistics that examine the presence of unit roots (non-stationary) for all variables. The study finds that all variables contain a unit root, implying that the null- hypothesis of the presence of a unit root at level cannot be rejected. Since the indices are found to be non-stationary at levels, the first differences for whole models are taken. The same tests are applied to the first differences of the indices and the results show that all the indices become stationary after first differencing. This result indicates that all variables are integrated of order one, I(1) and, then, we proceed to the Granger non-causality test as proposed by Toda and Yamamoto (1995) to examine the causal linkages between stock prices and the exchange rates.

Table 1: Unit Root Test

\begin{tabular}{|l|l|l|l|l|l|}
\hline Sample & Variables & Level & \multicolumn{2}{l|}{ First Difference } \\
\cline { 3 - 6 } & & ADF & PP & ADF & PP \\
\hline \multirow{5}{*}{ Daily } & SP & -1.7009 & -1.2312 & $-9.0919^{* * *}$ & $-42.3319^{* * *}$ \\
\cline { 2 - 6 } & ER & $-3.1889^{*}$ & -2.7432 & $-9.7530^{* * *}$ & $-43.4942^{* * *}$ \\
\cline { 2 - 6 } & US & -1.1901 & -1.2938 & $-11.6508^{* * *}$ & $-53.2131^{* * *}$ \\
\hline \multirow{3}{*}{ Weekly } & SP & -1.8775 & -1.5283 & $-7.7140^{* * *}$ & $-22.7279^{* * *}$ \\
\cline { 2 - 6 } & ER & $-3.3070^{*}$ & -2.9288 & $-7.7418^{* * *}$ & $-21.1129^{* * *}$ \\
\cline { 2 - 6 } & US & -0.9581 & -1.1619 & $-8.8582^{* * *}$ & $-25.0747^{* * *}$ \\
\hline
\end{tabular}

Note: $* * * *$ and $*$ indicate significance at $1 \%$ and $10 \%$ levels respectively. 
Table 2 shows the results of the bivariate Granger non-causality test for both daily and weekly indices. Using daily index, the results suggest there exists a unidirectional causality running from stock price to exchange rate. Interestingly, the weekly data suggests that there is bi-directional causality between exchange rates and stock price. In order to avoid possible misspecification bias of omitting important variables, we re-examine the causal relationship by adding the US stock prices. The results are shown in the Table 3 . The results for the daily and weekly data suggest that there is a strong evidence to support bidirectional causality between stock prices and exchange rates.

Table 2: Bivariate Granger Non-Causality Test Results

\begin{tabular}{l|l|l|l} 
& $\mathrm{ER}=/=>\mathrm{SP}$ & $12.9296^{* *}$ & $\mathrm{ER}==>\mathrm{SP}$ \\
Notes: & $* * * * *$ \\
& and ${ }^{*}$ indicate significant at 1,5 and 10 percent respectively. $=/=>$ indicates does not
\end{tabular} Granger cause. The optimum lag lengths are based on Akaike Information Criterion (AIC).

Table 3: Multivariate Granger Non-Causality Tests Results

\begin{tabular}{|l|l|l|l|}
\hline & Hypothesis & MWALD & Concluding remarks \\
\hline \multirow{4}{*}{ Panel A: Daily } & $\mathrm{SP}=/=>\mathrm{ER}$ & $12.3487^{* *}$ & $\mathrm{SP}==>\mathrm{ER}$ \\
\cline { 2 - 4 } & $\mathrm{ER}=/=>\mathrm{SP}$ & $11.0577^{*}$ & $\mathrm{ER}==>\mathrm{SP}$ \\
\cline { 2 - 4 } & $\mathrm{SP}=/=>\mathrm{US}$ & $27.5376^{* * *}$ & $\mathrm{SP}==>\mathrm{SP}$ \\
\cline { 2 - 4 } & $\mathrm{US}=/=>\mathrm{SP}$ & 0.8984 & $\mathrm{SP}=/=>\mathrm{SP}$ \\
\cline { 2 - 4 } & $\mathrm{ER}=/=>\mathrm{US}$ & 0.2431 & $\mathrm{ER}=/=>\mathrm{SP}$ \\
\cline { 2 - 4 } & $\mathrm{US}=/=>\mathrm{ER}$ & $17.1754^{* * *}$ & $\mathrm{SP}==>\mathrm{ER}$ \\
\hline & $\mathrm{SP}=/=>\mathrm{ER}$ & $23.8201^{* * *}$ & $\mathrm{JCI}==>\mathrm{ER}$ \\
\cline { 2 - 4 } & $\mathrm{ER}=/=>\mathrm{SP}$ & $19.2211^{* * *}$ & $\mathrm{ER}==>\mathrm{JCI}$ \\
\cline { 2 - 4 } & $\mathrm{SP}=/=>\mathrm{US}$ & 8.8827 & $\mathrm{SP}=/=>\mathrm{US}$ \\
\cline { 2 - 4 } & $\mathrm{US}=/=>\mathrm{SP}$ & $27.0334^{* * *}$ & $\mathrm{US}==>\mathrm{SP}$ \\
\cline { 2 - 4 } & $\mathrm{ER}=/=>\mathrm{US}$ & 3.1546 & $\mathrm{ER}=/=>\mathrm{US}$ \\
\cline { 2 - 4 } & $\mathrm{US}=/=>\mathrm{ER}$ & 1.4058 & $\mathrm{US}=/=>\mathrm{ER}$ \\
\hline
\end{tabular}

Notes: ${ }^{* * * * *}$ and ${ }^{*}$ indicate significant at 1,5 and 10 percent respectively. $=/=>$ indicates does not Granger cause. The optimum lag lengths are based on Akaike Information Criterion (AIC).

\section{CONCLUSION}

This study has examined the causal relationship between stock prices and exchange rate in Indonesia during the period of 1998 - 2007. Using both daily and weekly, we examined the issue by applying Toda and Yamamoto (1995) Granger non-causality test.

The results suggest that there is a strong evidence to support bi-directional causality between stock prices and exchange rates in Indonesia. The findings imply that both stock and foreign exchange markets in Indonesia are not informational efficient since information in one market can be utilized to make prediction the movement of other market. This finding is different from Ajayi et al. (1998), who found in Indonesia the causality running from stock prices to the exchange rate and also contrast with Granger et al. (2000) who concluded there was no support for any relationship in Indonesia. 
In line with Azman et al. (2003) and Phylaktis and Ravazzolo (2005), the US stock market is found to an important causing variable which acts as a medium to link foreign exchange and local stock markets.

For the purpose of policy making, any shocks in both stock and foreign exchange markets should be taken into consideration by the Indonesian authorities to design policies pertaining to its stock and exchange rate policies. In addition, to take advantage of financial integration and economic integration, greater liberalization will be necessary.

For the policy implication, the researchers suggest that respective government should be cautious in their implementation of exchange rates policies, given that such policies have effect on their stock market.

\section{ACKNOWLEDGEMENTS}

We are grateful for the financial support from UNIMAS and the Ministry of Higher Education through the Research Acculturation Collaborative (RACE) Grant No: RACE/e(4)/1251/2015 (07).

\section{REFERENCES}

Abdalla, I. and Murinde, V. (1997). Exchange rate and stock price interactions in emerging financial markets: evidence on India, Korea, Pakistan and the Philippines, Applied Financial Economics, 7, pp.25-35.

Akaike, H. (1974). A new look at the statistics model identification, IEEE Transactions on Automatic Control AC, 19, 716-723.

Aggarwal, R. (Fall 1981). Exchange rates and stock prices: a study of the U.S. capital markets under floating exchange rates. Akron Business and Economic Review, pp.7-12.

Ajayi, R. A., Friedman, J. and Mehdian, S. M. (1998). On the relationship between stock returns and exchange rates: tests of Granger casuality, Global Finance Journal, 9, pp.241-51.

Azman-Saini, W. N. W., M.S. Habibullah and M. Azali (2003). Stock Price and Exchange Rate Interactions in an Emerging Market, RISEC: International Review of Economics and Business, 50, 503-519.

Bahmani-Oskooee, M. \& Sohrabian, A. (1992). Stock Prices and the Effective Exchange Rate of the Dollar, Applied Economics, Taylor and Francis Journals, vol. 24(4), pp. 459-64, April.

Bodnar, G. M., and Gentry, W. M. (1993). Exchange Rate Exposure and Industry Characteristics: Evidence from Canada, Japan and the U.S., Journal of International Money and Finance, Vol.12, pp. 29-45.

Granger, C. W. J., Huang, B. N. and Yang, C. W. (2000). A bivariate casuality between stock prices and exchange rates: evidence from recent Asian flu, Quarterly Review of Economics and Finance, 40, pp.337-54.

Hamrita, M.E. and Trifi, A. (2011). The relationship between interest rate, exchange rate and stock price: A wavelet analysis. International Journal of Economics and Financial Isues, 1(4), 220-228.

Mavrotas, G., and R. Kelly (2001). Old Wine in New Bottles: Testing Causality Between Savings and Growth. The Manchester School, 69: 97-105.

Morley B. and Pentecost E.J, (2000). Common trends and cycles in G-7 countries exchange rates and stock prices, Applied Economics Letters, 7, pp.7-10

Nieh, C. C., and Lee, C. F., (2001). Dynamic relationship between stock prices and exchange rates for G7 countries The Quarterly Review of Economics and Finance 41, pp.477-490. 
Pan, M.S., Fok, R.C.W. and Liu, Y.A. (2007). Dynamic linkages between exchange rates and stock prices: Evidence from East Asian markets. International Review of Economics \& Finance, 16(4), 503-520.

Phylaktis, K. and Ravazzolo, F. (2005). Stock prices and exchange rate dynamics. Journal of International Money and Finance, Vol. 27 (7), pp. 1031-1053.

Qiao, Y., (1996). Stock Prices and Exchange Rates: Experiences in Leading East Asian Financial Centres - Tokyo, Hong Kong and Singapore. Singapore Economic Review 41, pp.47-56.

Saiti, B., Ali, A., Abdullah, N. and Sajilan, S. (2014). Palm Oil Price, Exchange Rate, and Stock Market: A Wavelet Analysis on the Malaysian Market. Eurasian Journal of Economics and Finance, 2(1), $13-27$.

Smyth R. and Nandha M. (2003). Bivariate causality between exchange rates and stock prices in South Asia, Applied Economics Letters, 10, pp.699-704

Toda, H.Y. and Yamamoto, T. (1995). Statistical inference in vector autoregressions with possibly integrated processes. Journal of Econometrics, Vol. 66 (1), pp. 225-250.

Yang S.Y and Doong S.C (2004). Price and Volatility Spillovers between Stock Prices and Exchange Rates: Empirical Evidence from the G-7 Countries, International Journal of Business and Economics, Vol. 3, No. 2, pp.139-153

Zapata, H. and Rambaldi A. (1997). Monte Carlo evidence on cointegration and causation. Oxford Bulletin of Economics and Statistics, vol. 59(2), pp. 285-298.

Zhao, H. (2010). Dynamic relationship between exchange rate and stock price: Evidence from China. Research in International Business and Finance, 24(2), 103-112.

Corresponding Author: Bakri Abdul Karim can be contacted at akbakri@unimas.my 